\title{
Temperature dependent dynamic flow behavior of an in-situ Ti-based bulk metallic glass
}

\section{composite}

J. Bai ${ }^{\text {a, }}$, J.S. Li ${ }^{a^{*}}$, J. Wang ${ }^{\text {a }}$, H.C. Kou ${ }^{\text {a }}$, P. K. Liaw ${ }^{\text {b }}$

a. State Key Laboratory of Solidification Processing, Northwestern Polytechnical University, Xi'an 710072, China.

b. Department of Materials Science and Engineering, University of Tennessee, Knoxville, TN 37996-2200, USA

\section{Abstract}

The deformation behavior of in-situ $\mathrm{Ti}_{48} \mathrm{Zr}_{20} \mathrm{Nb}_{12} \mathrm{Cu}_{5} \mathrm{Be}_{15}$ bulk metallic glass (BMG) composites was investigated within a wide range of temperature from $77 \mathrm{~K}$ to $573 \mathrm{~K}$ upon dynamic loading. The present BMG composites exhibit good plasticity (about 11\%) above the ambient temperature, but ductile to brittle transition occurs as the temperature lows. Further studies reveal that the deteriorated ability of dendrites to hinder the propagation of shear bands at low temperature is responsible for the present transition. With the decrease of temperature, the yield stress of the present BMG composite increases dramatically and the lower temperature also yields more obvious temperature rising in the fracture surfaces.

Keywords: Bulk amorphous alloys; Composites; Mechanical characterization; Plasticity; Ductile to brittle transition; Micromechanism;

${ }^{*}$ Corresponding author. Tel.:+86 298849 1074;

E-mail address: ljsh@nwpu.edu.cn. 


\section{Introduction}

Bulk metallic glasses (BMGs) have been considered to be promising structural engineering materials for lots of unique properties, such as high strength, high hardness, and large elastic limit [1-3]. However, their potential applications have been widely stymied by the brittle failure related to the adiabatic shear deformation mechanism [4]. During deformation, the macroscopic plastic deformation is narrowed in very few thin shear bands, which leads to significant softening in shear bands and causes the catastrophic brittle fracture of BMGs [1, $3-6]$.

Many intrinsic and extrinsic toughening strategies have been adopted to ameliorate the plasticity of BMGs. In intrinsic toughening methods, tuning a higher Poisson ratio or a lower ratio of the shear modulus to the bulk modulus has been adopted in some BMGs by carefully alloy designing [7, 8]. Compared with the strict compositional design of intrinsic toughening methods, the extrinsic toughening methods provide optional ways to improve the plasticity of BMGs with low intrinsic plasticity by synthesizing ex or in-situ BMG composites, surface modification $[9,10]$ et al. Among them, in-situ dendrite-reinforced BMG composites have been rendered as a kind of promising materials [11-13]. By introducing "soft" second crystalline phase, the strain localization can be homogenized and more shear bands are nucleated in the glass matrix $[14,15]$. Consequently, good plasticity and other unique properties have been obtained in these new materials $[12,16-18]$. To extend the application, their deformation behaviors subjected to different conditions have been investigated.

Up to now, a few studies have reported that the dynamic deformation behavior of these in-situ BMG composites. Lee et al. found that Zr-based BMG composites exhibited brittle fracture both at and above temperature upon dynamic deformation [19]. In addition, Chen et al. claimed that the brittle fracture at high strain rates was caused by the decrease of the shear toughness of dendrite [20]. More recently, Qiao et al. reported that Ti-based BMG composites can exhibit distinguishing ambient work-hardening ability [21] and the fracture stress increases with the increase of strain rates [22]. Jeon et al. [23] further suggested that dendrites size 
played a significant role on the dynamic plasticity. However, the influence of temperature on dynamic response of these in-situ BMG composites is scarcely studied. Dynamic deformation micromechanisms in these in-situ BMG composites are still far from clarification.

In the present study, deformation behaviors of a Ti-based in-situ dendrite / glass matrix composites were investigated upon dynamic deformation within a wide range of temperature from $77 \mathrm{~K}$ to $573 \mathrm{~K}$. The aim of the present study is to further uncover the underlying micromechanisms upon dynamic deformation in these in-situ BMG composites and promote their potential application.

\section{Materials and Methods}

Ti-based ingots with a normalized composition of $\mathrm{Ti}_{48} \mathrm{Zr}_{20} \mathrm{Nb}_{12} \mathrm{Cu}_{5} \mathrm{Be}_{15}$ were obtained by arc melting the mixture of Ti, $\mathrm{Zr}, \mathrm{Nb}, \mathrm{Cu}>99.99$ wt.\% and $\mathrm{Be}>99.95$ (wt.\%) in a Ti-getterd argon atmosphere. By the copper mould casting method, the rod-like samples with $3 \mathrm{~mm}$ in diameter were produced. Dynamic experiments were conducted on the Split Hopkinson Pressure Bar (SHPB) with a cryogenic box and furnace from the temperature of $77 \mathrm{~K}$ to $578 \mathrm{~K}$ at the strain rate of $1.3 \times 10^{3} / \mathrm{s}$. $\Phi 3 \mathrm{~mm}$ samples with an aspect ratio of $1: 1$ were well polished and prepared to make sure the parallel of two ends. The phase structure of the present BMG composite was ensured by the X-ray diffraction (XRD, DX2700) with a $\mathrm{Cu}\left(K_{a}\right)$ radiation. The as-casted microstructure and samples after deformation were observed by scanning electronic microscope (SEM, VEGA3 TESCAN). High resolution transmission electron microscope (HRTEM, Tecnai G2 F30) was used to further identity the microscopic structure evolution

\section{Results}

The microstructure of the present BMG composites is presented in Figure 1. It can be seen that the present BMG composite consists of the continuous matrix (grey contrast) and the second phase with a flower-like shape (white contrast). By image analysis, the volume fraction of second phase is approximately $52 \%$. The average size of second phase, which is characterized by the spanning length of individual dendrites [12], is about $20 \mu \mathrm{m}$ for 
the present BMG composite.

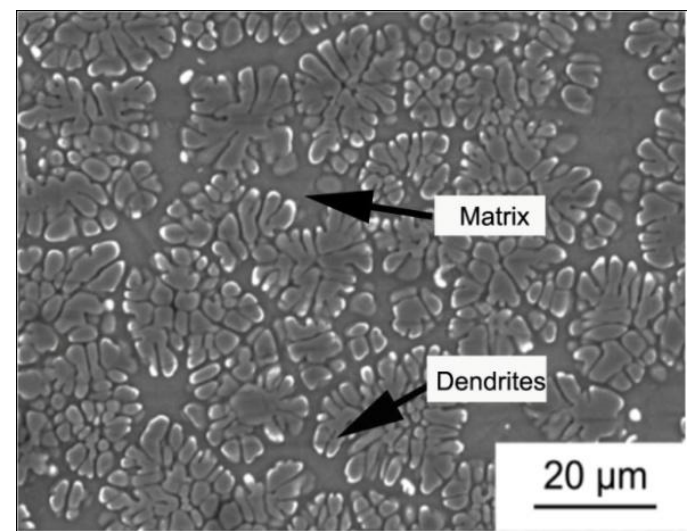

Figure 1 As-casted microstructure of the present $\mathrm{Ti}_{48} \mathrm{Zr}_{20} \mathrm{Nb}_{12} \mathrm{Cu}_{5} \mathrm{Be}_{15} \mathrm{BMG}$ composite.

The XRD pattern of the present BMG composite is shown in Figure 2. Sharp crystalline peaks of $\beta$-Ti ( $\mathrm{Zr}$,

$\mathrm{Nb}$ ) solution are superimposed on a broad scattering peak, confirming that the second phase is the Ti-rich solution with a body-centered cubic structure and the matrix has an amorphous structure. The selected area electron diffraction (SAED) pattern of the matrix characteristic of diffuse concentric rings in the inset of Figure 2 further indicates the monolithic amorphous nature of the matrix.

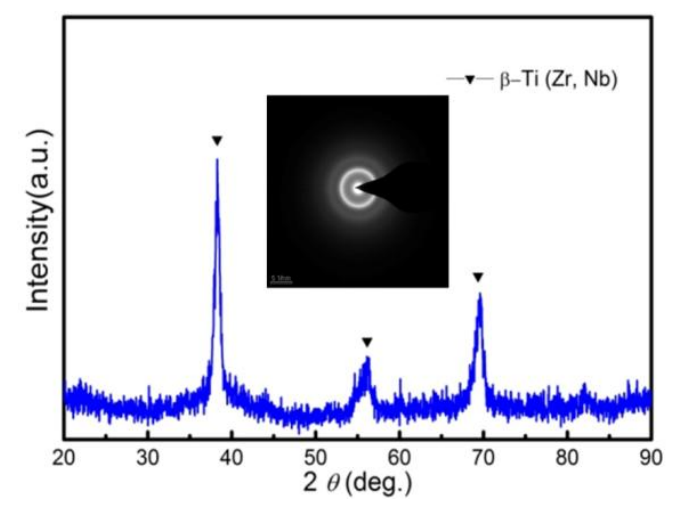

Figure 2 XRD pattern of the present BMG composite and the inset is the SAED of the matrix, further demonstrating the monolithic amorphous nature of the matrix.

The typical engineering stress vs. strain curves at the strain rate of $1.3 \times 10^{3} / \mathrm{s}$ from $573 \mathrm{~K}$ to $77 \mathrm{~K}$ are exhibited in Figure 3(a). The present BMG composite possesses about 1,570 MPa fracture stress at $573 \mathrm{~K}$. As the temperature decreases to $77 \mathrm{~K}$, the present BMG composite exhibits a significant temperature dependence that 
the fracture stress increases to 2,380 MPa. The variation of plasticity of the present BMG composites with the temperature is summarized in Figure 3(b). Above the ambient temperature, the plasticity of the present BMG composites is about $11 \%$ and reveals a negligible variation along with the decrease of temperature. However, when further lowering temperature, the plasticity sharply reduces to only about $4.5 \%$ and $3.2 \%$ for $223 \mathrm{~K}$ and $183 \mathrm{~K}$, respectively until brittle fracture occurs at cryogenic temperature, giving an implication that a ductile to brittle transition occurs in the present BMG composite upon dynamic deformation when lowering the temperature.
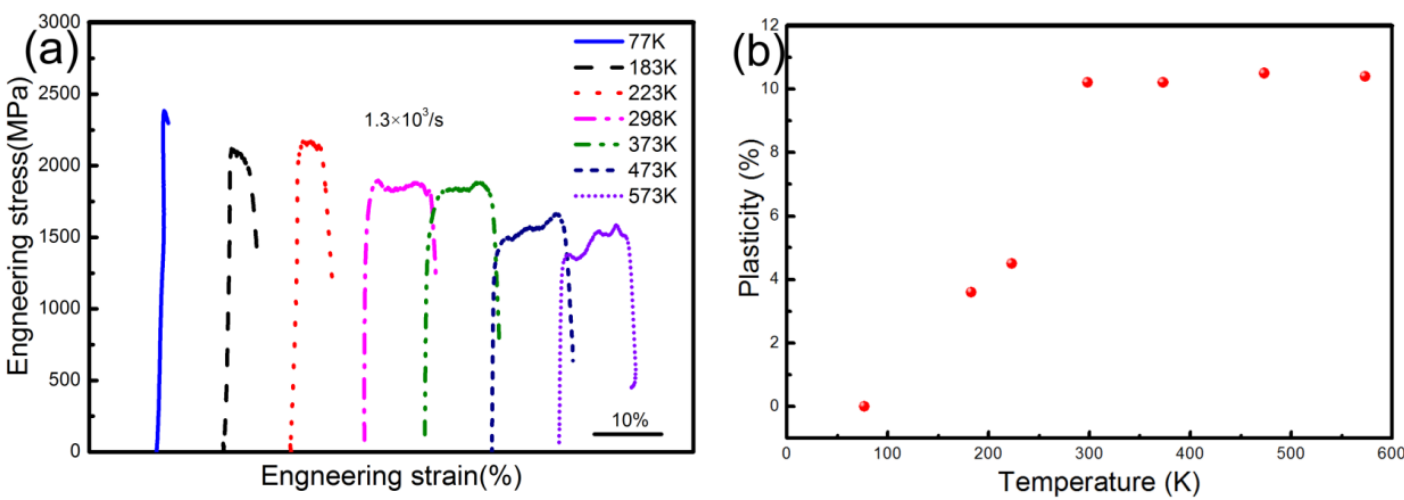

Figure 3 (a) Stress vs. strain curves of the present BMG composites at the temperature from $77 \mathrm{~K}$ to $573 \mathrm{~K}$. (b) the variation of plasticity with the temperature, revealing that a ductile to brittle transition occurs in the present BMG composites.

Figure 4 is the SEM images of the broken samples after deformation at $573 \mathrm{~K}, 298 \mathrm{~K}$ and $77 \mathrm{~K}$. As shown in Figure 4(a), (c) and (e), all the samples follow shear failure with fracture angles of less than $45^{\circ}$, which deviate from the maximum shear stress planes, implying the significant effect of normal stress on the fracture behavior of present BMG composite [24]. The corresponding magnified images of lateral surfaces at $573 \mathrm{~K}, 298 \mathrm{~K}$ and 77 $\mathrm{K}$ are shown in Figure 4(b), (d) and (f), respectively. Abundant shear bands, denoted by black arrows, can be observed in Figure 4(b) and (d), corresponding to their remarkable plasticity upon dynamic loading. However, the sample fractured at the cryogenic temperature reveals a single shear band dominated fracture without any 
minor shear bands, as exhibited in Figure 4(f). These obvious differences means that the temperature plays a crucial role on the mutual effects between dendrites and the glass matrix.
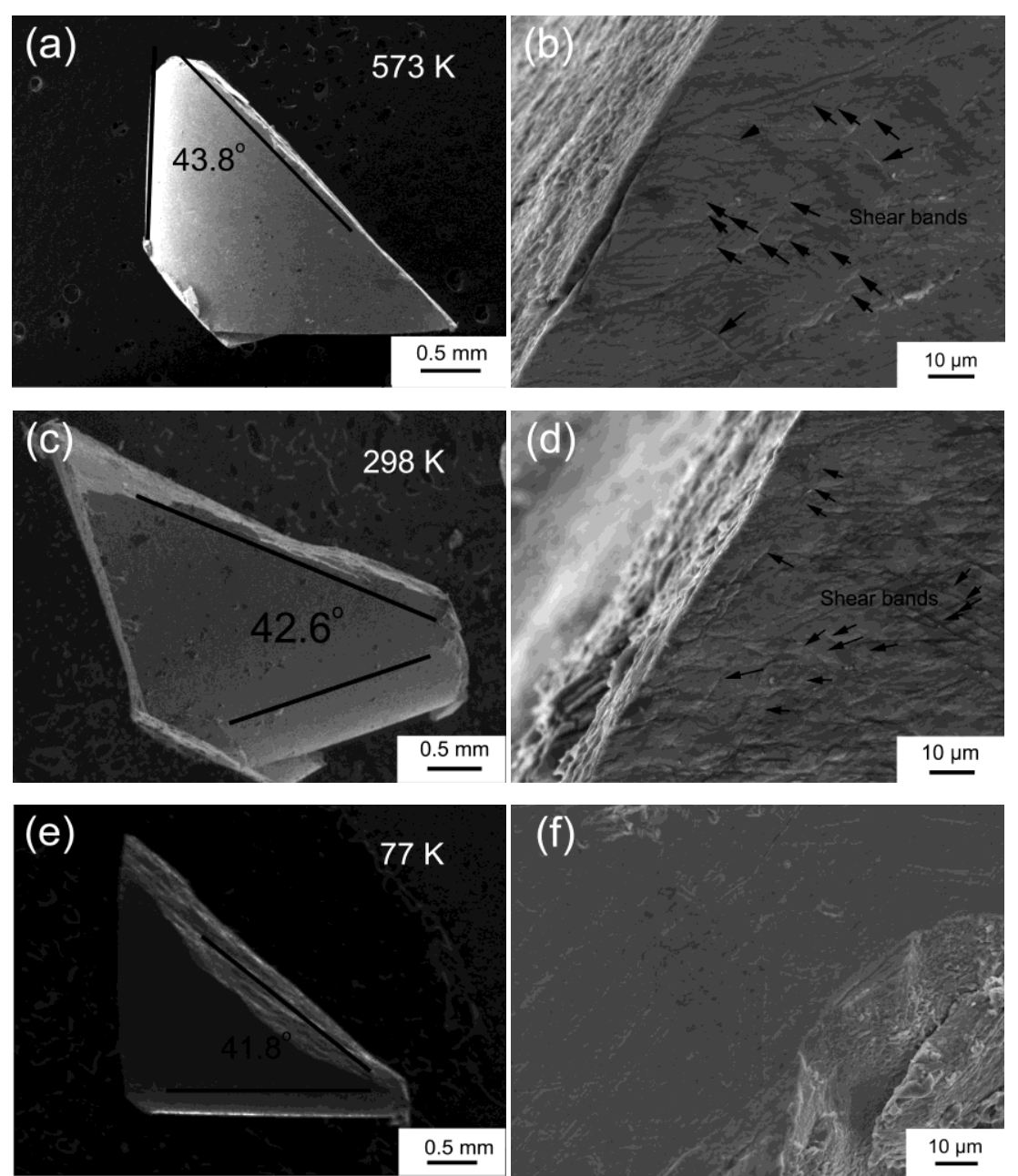

Figure 4 SEM images of the fractured samples upon dynamic deformation at 573K (a) $298 \mathrm{~K}$ (c) and $77 \mathrm{~K}$ (e), respectively. (b), (d) and (f) showing the corresponding magnified lateral surfaces.

The fractographs of the present BMG composites at different temperature are displayed in Figure 5. After fracture, all the fracture surfaces are covered by melting layers, which indicates the dramatically temperature rising in the critical shear band [25]. In addition, it's worth noting that the fracture surface become much coarser when the temperature lows to $77 \mathrm{~K}$, suggesting more severe adiabatic temperature rising at lower temperature for the BMG composites during dynamic deformation. 

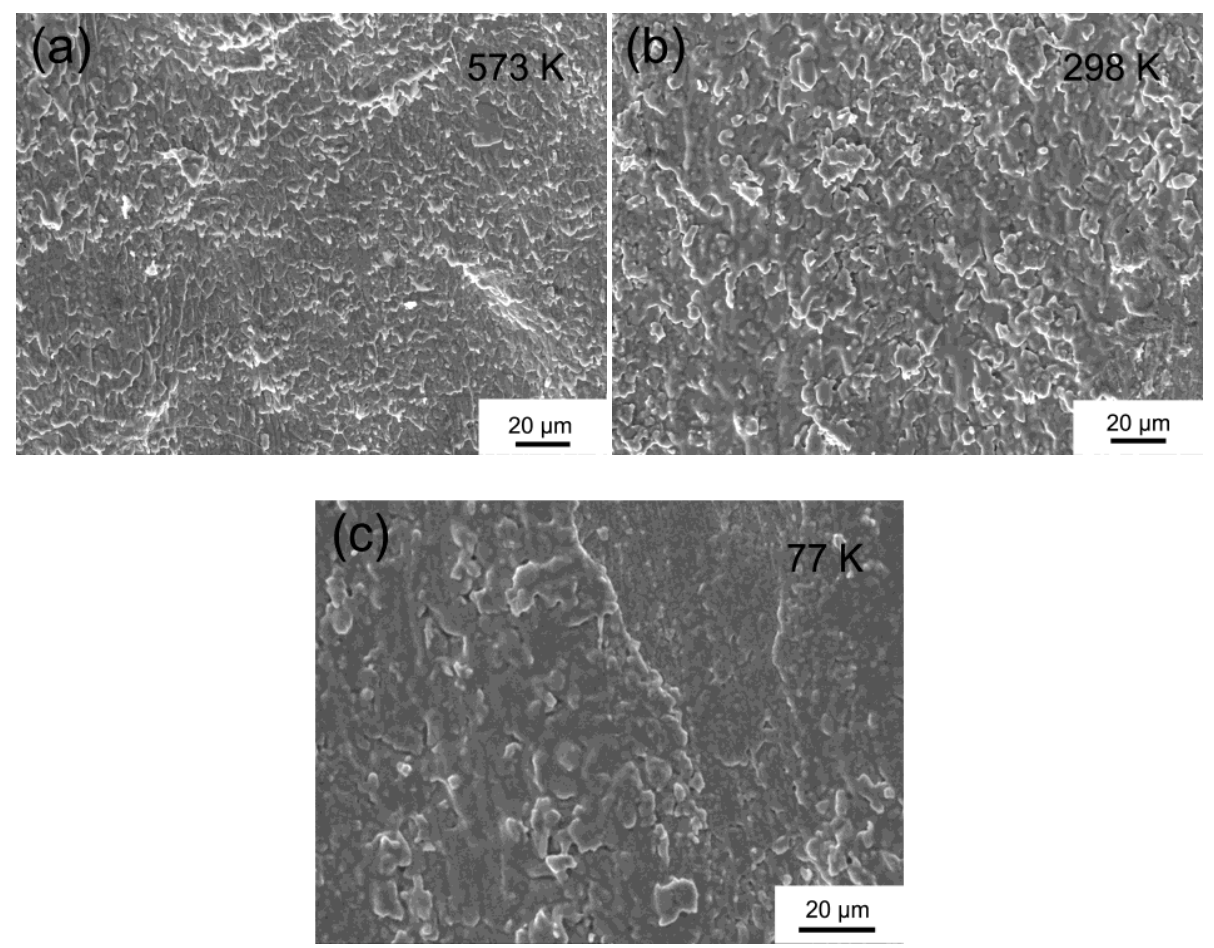

Figure 5 Fractographs of the present BMG composites after deformed at $573 \mathrm{~K}$ (a), $298 \mathrm{~K}$ (b) and $77 \mathrm{~K}$ (c), respectively.

\section{Discussion}

During deformation, compared with the ex-situ BMG composites, these in-situ dendrite-reinforced BMG composites possess a strong interface between the crystalline dendrites and the glass matrix [26, 27]. This ensures that the effective loading transfer and the coordination of the dendrite on the glass matrix even upon dynamic deformation or at low temperatures [21, 28, 29]. During deformation, the shear bands initiate at the interfaces between the dendrites and the glass matrix due to the stress concentration induced by the mismatch [30]. These "soft" dendrites act as heterogeneities to stimulate the multiplication of shear bands and absorb excessive propagation of single shear bands [14, 21]. As shown in Figure 4(b) and (d), amounts of shear bands are generated on the lateral surfaces, which indicates that the dendrites can still effectively accommodate the macroscopic plastic deformation and cause the prevailing of shear bands at or above the ambient temperature.

Thus, the present BMG composite exhibits distinguished plasticity even upon dynamic deformation. 
As shown in Figure 3(b), the present BMG composite shows an obvious ductile to brittle transition with the temperature decrease upon dynamic deformation. Under quasi-static deformation, the temperature-dependent ductile to brittle transition in BMG composites has been attributed to the early brittle failure of dendrites at cryogenic temperature [31]. However, our previous studies have demonstrated that the dendrites in present BMG composite still own good plasticity at low temperature $[18,29]$. Additionally, the shear failure in Figure 3 also implies that the fracture is still dominated by the critical shear band. Therefore, the ductile to brittle transition in the present BMG composite upon dynamic deformation lies in the mechanism differing from that previous study under the quasi-static deformation [31]. For the dendrites in the present BMG composites with a body-centered cubic structure, it has been widely documented that the toughness is very sensitive to the temperature. The lower temperature, the worsen toughness the dendrites has, exhibiting a typical ' $\mathrm{S}$ ' relationship with temperature [32, 33]. In addition, previous studies $[12,14,20]$ have indicated that the toughness of the dendrites has a great influence on the propagation of shear bands. The higher toughness of dendrites will benefit the impediment of shear bands and the nucleation of more shear bands $[14,20]$. Thus, the ability of dendrite to inhibit the propagation of shear bands reduces along with the decrease of temperature. In other words, the shear bands are more vulnerable to cut and pass the dendrites at low temperature rather than stop inside them.

To further clarify the micromechanism of ductile to brittle transition in the present BMG composites. Figure 6(a) and (b) represent the TEM bright-field images of the samples after fracture at $298 \mathrm{~K}$ and $77 \mathrm{~K}$, respectively. As white circles display in Figure 6(a), it can be clearly seen that shear bands denoted by black arrows are caught by the dendrites after a short penetration. In addition, multiple dislocations, marked by white arrow, can also be observed in the vicinity of shear band tip as shown in the white rectangular region. This indicates that the dendrite with high toughness at ambient temperature can effectively block the propagation of shear bands. Once the shear bands spread into the dendrites, the adiabatic shear energy can be promptly consumed by the formation 
of multiple dislocation corresponding to the plastic deformation in dendrites. However, differing from the observation in Figure 6(a), the shear bands marked by the dash line pass through the dendrites rather than be absorbed at $77 \mathrm{~K}$ as shown in Figure 6(b). Sharp stepped interfaces about 200-300 nm in height can also be observed due to the severely relative shear movement between dendrites and the matrix $[14,30]$, denoting by the white zigzag line. Both the corresponding selected area diffraction patterns in the insets of Figure 6(a) and (b) were identified as the [001] axis of $\beta$-Ti dendrites, which further confirms that no phase transition takes place in the dendrites upon dynamic deformation at both temperature. Figure 6(c) and (d) are the HRTEM images and the corresponding SAEDs of the matrix after deformed at $298 \mathrm{~K}$ and $77 \mathrm{~K}$, respectively. Mazelike structures and concentric rings verify that the matrix still keeps a monolithic amorphous structure without nanocrystallization after dynamic deformation, indicating the good thermal stability of the matrix. Therefore, based on above discussion, it's reasonable to deduce that the deteriorated ability of dendrites to hinder the propagation of shear bands at low temperature is responsible for the ductile to brittle transition of the present BMG composite. Meanwhile, Yu et al. [34] has indicated that the Poisson ratio of glass matrix also decreases along with the decreasing temperature, which means that higher resistance to the nucleation of the shear bands and easier dilatation of the crack tips. Thus, the intrinsic plasticity and deformation ability of the glass matrix decreases as the temperature lows $[34,35]$, which could further aggravate the brittleness of the present BMG composites at the cryogenic temperature. 

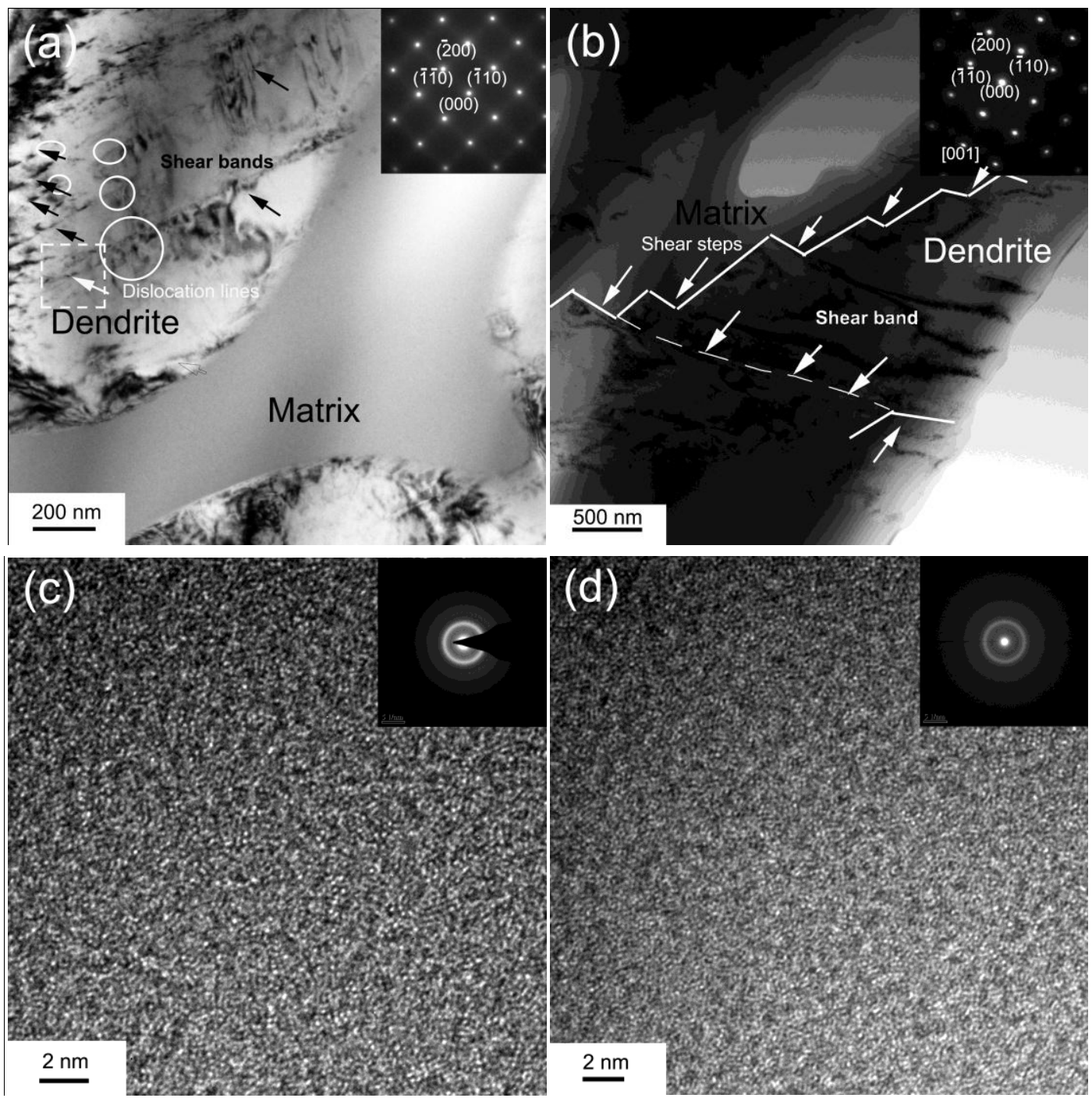

Figure 6 TEM images of the present BMG composite after fracture at $298 \mathrm{~K}$ (a) and $77 \mathrm{~K}$ (b), respectively. The insets of them are the corresponding SAED patterns of the dendrites. (c) and (d) The HRTEM images and SAED of the glass matrix, corresponding to (a) and (b), respectively, indicating that no nanocrystalline occurs in the glass matrix upon dynamic deformation.

The variation of the yield stress with the temperature is exhibited in Figure 7. During deformation, the 'soft' dendrites which have lower yield stress than the matrix are considered to yield firstly and initiate the yielding of the whole BMG composite [14]. According to the Varshni model [36], the elastic constants of materials have been indicated to be inversely proportional to the temperature. That is, the lower temperature, the higher elastic and shear modulus in the dendrites and the glass matrix [34,36]. As a consequence, these "stiffening effects" 
also cause higher resistance to the dislocation movement in the dendrites and the nucleation of shear bands in the glass matrix. Thus, the yield strength of the present BMG composite increases as the temperature decreases.

To better describe the relationship between the temperature and the yield stress in the present BMG composite during dynamic deformation, the Johnson-Cook (J-C) plastic model is employed in the present BMG composite [22, 37],

$$
\sigma=\left(A+B \varepsilon_{p}{ }^{n}\right)(1+C \ln \dot{\varepsilon})\left[1-\left(\frac{T-T_{r}}{T_{m}-T_{r}}\right)^{m}\right]
$$

here, $A, B, C, m$ are material constants, respectively. $\varepsilon_{p}$ is the equivalent strain. At yielding point, $\varepsilon_{p}$ is taken zero.

$\dot{\varepsilon}$ is the dimensionless strain rate. $T$ is the current absolute temperature and $T_{m}$ is and the melting temperature of dendrites, about $1600 \mathrm{~K}$ for the present BMG composite. The reference temperature, $T_{r}$, can take as $77 \mathrm{~K}$. Because of all samples were deformed at the same strain rate of $1.3 \times 10^{3} / \mathrm{s}$, then, irrespective of the influence of strain rates, Equation (1) can be reduced to Equation (2),

$$
\sigma=D \times\left[1-\left(\frac{T-T_{r}}{T_{m}-T_{r}}\right)^{m}\right]
$$

where, $D$ is a constant. As fitted in Figure 7 by Equation (2), the constitutive correlation between the temperature and the yield stress for the present BMG composite upon dynamic deformation can be obtained as $\sigma=2381\left(1-[(T-77) / 1327]^{0.854}\right)$.

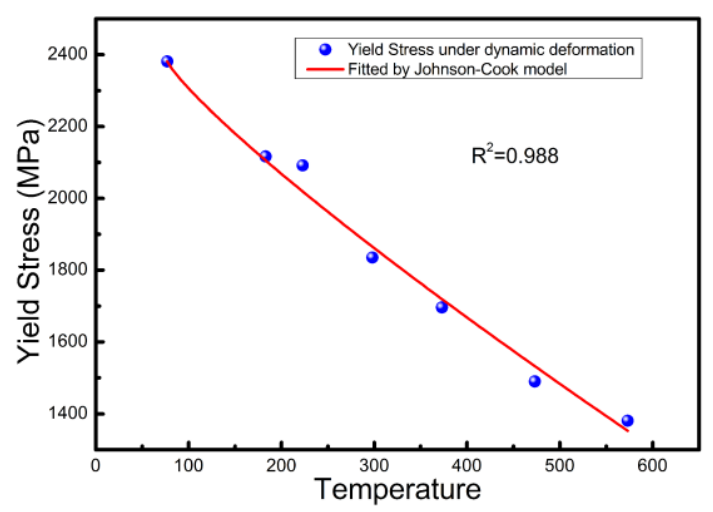

Figure 7 The dependence of the yield stress on the temperature at the strain rate of $1.3 \times 10^{3} / \mathrm{s}$ and the fitting 
results by $\mathrm{J}-\mathrm{C}$ model

Furthermore, as displayed in Figure 5, more abundant melting traces can be observed on the fracture surface at lower temperature, which is obviously inconsistent with the previous findings in monolithic BMG that the higher temperature, the more melting layer in the fracture surfaces [38], demonstrating that the temperature exerts different effects on fracture feature of the present BMG composites. During deformation, the formation of liquid layers can be ascribed to the melting of the glass matrix due to the stored high elastic energy release in instantaneous fracture $[25,38]$. As aforementioned, the low temperature worsens the absorption capacity of dendrites to the shear energy, i.e. less energy can be consumed by the multiplication of dislocation in the dendrites and more energy will dissipate as the heat due to adiabatic shear [31]. Meanwhile, the melting is also aggravated by higher stored elastic energy corresponding to the greatly increased fracture strength at low temperature. Therefore, more obvious temperature rising in the fracture surfaces for the present BMG composites at lower temperature.

\section{Conclusions}

Dynamic deformation behavior of in-situ dendrite-reinforced BMG composites $\mathrm{Ti}_{48} \mathrm{Zr}_{20} \mathrm{Nb}_{12} \mathrm{Cu}_{5} \mathrm{Be}_{15}$ was investigated within a wide range of temperature from $77 \mathrm{~K}$ to $573 \mathrm{~K}$. The composites possess large plasticity above the ambient temperature, which can be attributed to the effective accommodation of dendrites to the matrix by inducing the multiplication of shear bands. With the decrease of temperature, a ductile to brittle transition can be observed upon dynamic loading. The deteriorated ability of dendrite to hinder the propagation of shear bands is believed to result in the present transition. Due to the higher resistance to the dislocation movement in the dendrites and the nucleation of shear bands in the glass matrix related to the increased elastic constants at lower temperature, the strength of the present BMG composite dramatically increases with reducing testing temperature and the correlation between yield stress and temperature can be expressed as $\sigma=2381\left(1-[(T-77) / 1327]^{0.854}\right)$. The lower temperature also yields more obvious temperature rising in the 
fracture surfaces.

\section{Acknowledgements}

J.S.Li would like to acknowledge the Fundamental Research Fund of Northwestern Polytechnical University (NPU) (JC20120203), Specialized Research Fund for the Doctoral Program of Higher Education (20136102120007) and the Program of Introducing Talents of Discipline to Universities (No. B08040). P.K.Liaw. appreciates the supports of National Science Foundations (DMR-0909037, CMMI-0900271, and CMMI-1100080) and the Department of Energy (DOE). J.Bai thanks for the fellowship support of NPU and China Scholarship Council.

\section{References}

[1] A. Peker, W. Johnson, Appl. Phys. Lett., 63 (1993) 2342-2344.

[2] H. Li, C. Fan, K. Tao, H. Choo, P.K. Liaw, Adv. Mater., 18 (2006) 752-754.

[3] W.H. Wang, C. Dong, C.H. Shek, Mater. Sci. Eng., A: R, 44 (2004) 45-89.

[4] B. Yang, M.L. Morrison, P.K. Liaw, R.A. Buchanan, G. Wang, C.T. Liu, M. Denda, Appl. Phys. Lett., 86 (2005) 141904

[5] W. Ma, H. Kou, J. Li, H. Chang, L. Zhou, J. Alloys Compd., 472 (2009) 214-218.

[6] A.L. Greer, Y.Q. Cheng, E. Ma, Mater. Sci. Eng., A: R, 74 (2013) 71-132.

[7] J.J. Lewandowski, M. Shazly, A. Shamimi Nouri, Scr. Mater., 54 (2006) 337-341.

[8] S.F. Guo, J.L. Qiu, P. Yu, S.H. Xie, W. Chen, Appl. Phys. Lett., 105 (2014) 161901.

[9] W. Chen, K.C. Chan, P. Yu, G. Wang, Mater. Sci. Eng., A, 528 (2011) 2988-2994.

[10] W. Chen, K.C. Chan, S.H. Chen, S.F. Guo, W.H. Li, G. Wang, Mater. Sci. Eng., A, 552 (2012) 199-203.

[11] C.C. Hays, C.P. Kim, W.L. Johnson, Phys. Rev. Lett., 84 (2000) 2901-2904.

[12] D.C. Hofmann, J.-Y. Suh, A. Wiest, G. Duan, M.-L. Lind, M.D. Demetriou, W.L. Johnson, Nature, 451 
(2008) 1085-1089.

[13] U. Ku $\square$ hn, J. Eckert, N. Mattern, L. Schultz, Appl. Phys. Lett., 80 (2002) 2478.

[14] J.W. Qiao, A.C. Sun, E.W. Huang, Y. Zhang, P.K. Liaw, C.P. Chuang, Acta Mater., 59 (2011) 4126-4137.

[15] R.T. Ott, F. Sansoz, J.F. Molinari, J. Almer, K.T. Ramesh, T.C. Hufnagel, Acta Mater., 53 (2005) $1883-1893$

[16] J.W. Qiao, Y. Zhang, H.L. Jia, H.J. Yang, P.K. Liaw, B.S. Xu, Appl. Phys. Lett., 100 (2012) 121902.

[17] G. Chen, J.L. Cheng, C.T. Liu, Intermetallics, 28 (2012) 25-33

[18] J. Bai, H.C. Kou, J. Wang, J.S. Li, R. Hu, Mater. Lett., 117 (2014) 228-230.

[19] D.-G. Lee, Y.G. Kim, B. Hwang, S. Lee, Y.T. Lee, Mater. Sci. Eng., A, 472 (2008) 316-323.

[20] J.H. Chen, M.Q. Jiang, Y. Chen, L.H. Dai, Mater. Sci. Eng., A, 576 (2013) 134-139.

[21] J.W. Qiao, H.Y. Ye, Y.S. Wang, S. Pauly, H.J. Yang, Z.H. Wang, Mater. Sci. Eng., A, 585 (2013) 277-280.

[22] J.W. Qiao, M.Y. Chu, L. Cheng, H.Y. Ye, H.J. Yang, S.G. Ma, Z.H. Wang, Mater. Lett., 119 (2014) 92-95.

[23] C. Jeon, M. Kang, C.P. Kim, H.S. Kim, S. Lee, Mater. Sci. Eng., A, 579 (2013) 77-85

[24] Z.F. Zhang, J. Eckert, L. Schultz, Acta Mater., 51 (2003) 1167-1179.

[25] Y. Zhang, W. Xu, H. Tan, Y. Li, Acta Mater., 53 (2005) 2607-2616.

[26] R.L. Narayan, P.S. Singh, D.C. Hofmann, N. Hutchinson, K.M. Flores, U. Ramamurty, Acta Mater., 60 (2012) 5089-5100.

[27] J.W. Qiao, S. Wang, Y. Zhang, P. Liaw, G. Chen, Appl. Phys. Lett., 94 (2009) 151905.

[28] C. Jeon, M. Kang, C.P. Kim, H.S. Kim, S. Lee, Mater. Sci. Eng., A, 579 (2013) 77-85.

[29] J.S. Li, J. Bai, J. Wang, H.C. Kou, R. Hu, H.Z. Fu, Mater. Des., 53 (2014) 737-740.

[30] K.B. Kim, J. Das, F. Baier, J. Eckert, Appl. Phys. Lett., 86 (2005) 171909.

[31] J.W. Qiao, P.K. Liaw, Y. Zhang, Scr. Mater., 64 (2011) 462-465. 
[32] A.A. Johnson, Philos. Mag., 7 (1962) 177-196.

[33] M.F. Ashby, J.D. Embury, Scr. Metall., 19 (1985) 557-562.

[34] P. Yu, K.C. Chan, W. Chen, L. Xia, Phil. Mag. Lett., 91 (2010) 70-77.

[35] G.N. Greaves, A.L. Greer, R.S. Lakes, T. Rouxel, Nature Mater., 10 (2011) 823-837.

[36] Y. Varshni, Phys. Rev. B, 2 (1970) 3952-3958.

[37] G.R. Johnson, W.H. Cook, Eng. Fract. Mech., 21 (1985) 31-48.

[38] Y. Huang, W. Zheng, F. He, J. Shen, Mater. Sci. Eng., A, 551 (2012) 100-103. 